\title{
O legado do Manifesto de 32 à educação bra- sileira: os desafios persistem
}

Maria Cristina Gomes Machado Universidade Estadual de Maringá

Carlos Henrique de Carvalho Universidade Federal de Uberlândia

\section{Resumo}

presente artigo propõe uma (re) leitura do Manifesto dos Pioneiros da Educação Nova, decorridos mais de oitenta anos de sua publicação. Nele, estão contidas as principais discussões em torno da educação pública e privada, bem como balizou os debates no âmbito da reconstrução educacional do país. Seus signatários enfatizam a premência de se criar um sistema nacional de educação para fazer frente às dificuldades enfrentadas pelo Brasil, fossem estes problemas de ordem política, econômica ou social. Os princípios do Manifesto expressam a necessidade de racionalizar e modernizar o Estado, via instrução pública, tendo em vista a modernização da nação.

Palavras-chave: Educação. Manifesto dos Pioneiros da Educação Nova. Modernizar e racionalizar o Estado.

\section{The legacy of the Manifest of 32 to Brazilian Education: challenges persist}

\begin{abstract}
This article proposes a re-reading of the "Manifesto dos Pioneiros da Educação Nova", eighty years or more after its publication. In this document, the main discussions about public and private education are registered. It functioned as a pattern for the educational reconstruction in this country. Those who signed it stressed the need to create a national system of education, in order to face the difficulties, which Brazil struggled with, either in the political or economic and social levels. The principles of the "Manifesto" expressed the need to rationalize and to modernize the State, by means of the public instruction, with the purpose of modernizing the nation.

Keywords: Education. Manifest of Pioneers of Education. Modernize and rationalize the State.
\end{abstract}




\section{El legado del Manifiesto de los 32 la educación brasileña: retos siguen siendo}

\section{Resumen}

Este trabajo propone una (re) lectura del Manifiesto de los Pioneros Nueva Educación, después de más de ochenta años de su publicación. En ella figuran los principales debates de la educación pública y privada y mantenido a flote las discusiones dentro de la reconstrucción educativa. Los firmantes hacen hincapié en la urgencia de crear un sistema nacional de educación para cumplir con las dificultades que enfrentan Brasil, fueron estos problemas de orden político, económico o social. Los principios del Manifiesto expresan la necesidad de racionalizar y modernizar el Estado, a través de la educación pública, teniendo en cuenta la modernización de la nación.

Palabras clave: Educación. Manifiesto de los Pioneros de la Nueva Educación. Modernizar y racionalizar el Estado.

\section{Introdução}

Este artigo tem por finalidade apresentar uma (re)leitura do Manifesto dos Pioneiros da Educação Nova (MANIFESTO..., 1932) passados mais de oitenta anos da publicação, dirigido ao povo e ao governo. $\bigcirc$ esforço em (re)visitar, novamente, este documento decorre da sua atualidade para a compreensão do quadro educacional brasileiro. As propostas de reconstrução educacional no Brasil, defendidas pelos seus signatários, tomavam como base a urgência de reorganização a educação brasileira, buscando alternativas para a resolução dos problemas de ordem política, econômica ou social que marcaram os anos de 1930. Neste sentido, mudanças substanciais em âmbito nacional far-se-iam importantes para a implementação de políticas com vistas a superar o quadro caótico da educação escolar desde o jardim de infância até o ensino superior. $\bigcirc$ jornal $\bigcirc$ Estado de $S$. Paulo o publicou em primeira mão, posteriormente, foi publicado Companhia Editora Nacional, tornando-se um marco histórico para o entendimento da História da Educação Brasileira. Nele, está contida uma síntese diagnóstica da situação da educação nacional, acompanhada de prescrições precisas para reverter o quadro traçado, 
permeado de um novo discurso educacional comprometido com uma sociedade industrializada e democrática.

Manifesto originou de discussões de educadores e, portanto, foi elaborado, pela sociedade civil, no sentido de balizar a educação no país, ou melhor, estabelecer uma base legal com vistas à projeção de "metas" a serem alcançadas ao longo de alguns anos, abrangendo diversos aspectos da educação brasileira do período em tela, isto é, o panorama sócio educacional dos anos de 1930.

Entretanto, passada mais de uma década do século XXI, os educadores foram consultados e o governo propôs um novo Plano Nacional de Educação (PNE), por meio da Lei n 13.005, de 25 de junho de 2014 (BRASIL, 2014). Muitos dos desafios denunciados pelos manifestantes de 1932 permanecem sem solução no que se refere à educação brasileira. A título ilustrativo, citamos o art. $2^{\circ}$ que apresenta as diretrizes do PNE: I erradicação do analfabetismo; || universalização do atendimento escolar; III superação das desigualdades educacionais, com ênfase na promoção da cidadania e na erradicação de todas as formas de discriminação; IV melhoria da qualidade da educação; V formação para o trabalho e para a cidadania, com ênfase nos valores morais e éticos em que se fundamenta a sociedade; VI promoção do princípio da gestão democrática da educação pública; VII promoção humanística, científica, cultural e tecnológica do País; VIII estabelecimento de meta de aplicação de recursos públicos em educação como proporção do Produto Interno Bruto - PIB, que assegure atendimento às necessidades de expansão, com padrão de qualidade e equidade; IX valorização dos (as) profissionais da educação; $X$ promoção dos princípios do respeito aos direitos humanos, à diversidade e à sustentabilidade socioambiental.

Ao tomarmos o PNE e suas diretrizes, percebemos os desafios históricos da educação brasileira no século XX e início do século XXI, os quais, de certa forma, também já eram pontos de fervorosos debates entre os educadores que assinaram o Manifesto de 32, com exceção dos incisos VI e X do referido art. $2^{\circ}$ PNE. Por outro lado, aquilo que se coloca na atualidade como importantes metas educacionais já haviam sido elencadas em 1932. Em linhas gerais, a redação foi atualizada e novas temáticas foram incluídas, como a questão da gestão democrática, o respeito à diversidade e sustentabilidade, contudo um estudo atento do documento de 1932 nos permite constatar que velhos problemas persistem e para resolvê-los propõem-se velhas soluções, sem 
legado do Manifesto de 32 à educação brasileira: os desafios persistem

atentarmos para a lentidão e dificuldade de saná-los. Para a compreensão dessas dificuldades, consideramos urgente a (re)leitura do Manifesto na relação estreita com as necessidades do país em uma nova etapa da organização do Estado em um novo contexto social.

A década de 1930 trazia, em seu bojo, os conflitos oriundos da crise internacional que culminou na queda da bolsa de Nova York, como resultado da reorganização do capital impelida pelos conflitos resultantes da Primeira Guerra Mundial (1914-1918) e a Revolução Russa (1917), novos desafios se colocavam com o imperialismo dos países industrializados e com o ineditismo da experiência socialista. As transformações desencadeadas levaram a divulgação de um novo ideário educacional, iniciado no final do século XIX e começo do XX, especialmente na Europa e nos Estados Unidos'.

No Brasil com a experiência republicana inaugurada em 1889 colocou em cena o debate sobre a importância da educação escolar e sua extensão às classes populares; para tanto, exigia-se o estabelecimento de uma educação que envolvesse uma fração maior da população brasileira em idade escolar do que a atendida no período imperial.

Com base na educação, divulgar-se-ão novos princípios, constituindo-se em um projeto nacional republicano e federativo formando a nacionalidade brasileira. Para tanto, a modernização do Estado brasileiro era premente. Berman (1988) destaca que essa configuração resultava das transformações da vida moderna, ao longo dos séculos XVI e XX, decorrentes das descobertas nas ciências físicas, da industrialização, do crescimento urbano, da consolidação dos Estados nacionais, da expansão do mercado capitalista.

Essas mudanças, em âmbito mundial, consubstanciaram-se no debate sobre a necessidade de escolarização das crianças brasileiras, já iniciado no período imperial, e tomaram uma tônica acentuada nos quarenta anos iniciais República. Esse debate foi-se manifestando na forma de políticas educacionais expressas na legislação educacional, com promessa de democratização e uniformização do ensino para atender às diferentes classes que constituem a sociedade. As intenções esbarravam na lentidão de expansão do ensino, assim a ideia de racionalizar a educação para modernizar o Estado, por meio da vulgarização da ciência, não surtiam os efeitos desejados.

Para essa racionalização, as ciências tornam-se conhecimentos importantes. Sobre o papel da ciência, recorremos a Habermas (2000) que explicita 
a relação entre a modernidade e o racionalismo ocidental. Para esse autor, há uma busca racional, sistemática, especializada e incessante por parte da ciência para tornar o pessoal treinado e especializado tanto na esfera estatal como na econômica. Esses aspectos são elementos que ganharam importância para a ordem social. $\bigcirc$ referido autor afirma que nenhum país do ocidente experimentou a absoluta e completa dependência da existência de uma organização de funcionários altamente especializados e treinados. Habermas (2000) defende a ideia de que há relação interna entre a modernidade e o racionalismo ocidental, assim as ciências empíricas modernas, as artes tornadas autônomas e as teorias morais e jurídicas, fundamentadas em princípios, formaram esferas culturais de valor que possibilitaram processos de aprendizado de problemas teóricos, estéticos ou prático-morais.

A modernização, nessa perspectiva, pode ser entendida como processos históricos pluridimensionais, que permitem vislumbrar a emergência de instituições, de valores, de concepções, de atitudes, de modos específicos de vivência do tempo, de apropriações do espaço, de produção e reprodução material, de organização da vida política, econômica e social e de vivências subjetivas, que redefiniram, de fato, o projeto civilizatório acidental.

processo de modernização brasileiro pode ser entendido como um movimento contínuo que perpassou vários âmbitos da sociedade - políticos, econômicos e educacionais -, no sentido de buscar uma base científica que oferecesse as condições necessárias ao país de conquistar uma organização política moderna, ancorada em bases do projeto liberal, mas disseminada a partir das reformas educacionais, cuja intenção era formar o povo brasileiro (projeto civilizador) e promover o desenvolvimento do país.

Para Faria Filho (2000), ainda no final do século XIX, Rui Barbosa propôs reformar todo o sistema de instrução do Brasil, apresentando parecer sobre a importância de mudar as condições de oferta da instrução pública no Brasil, transformando-o em um sistema nacional de ensino centralizado, uniformizado, funcionando com coerência e organicidade, assumindo sua condição moderna.

Era notório o número expressivo de analfabetos no país, posto como um mal crônico (FARIA FILHO, 2000). Palavras como educação, instrução, civilização, moralização e erradicação do analfabetismo deveriam ser palavras de ordem para o Estado. $O$ processo de modernização brasileiro estava 
legado do Manifesto de 32 à educação brasileira: os desafios persistem

permeado pela crença de que o desenvolvimento científico era fundamental para levar o Brasil a uma organização política moderna, baseada no projeto liberal, disseminando-se a partir das reformas educacionais, com o objetivo de contribuir com a formação da sociedade brasileira pari passu com o desenvolvimento do país.

Com base em dados fornecidos pelo Instituto Brasileiro de Geografia e Estatística (ANUÁRIO ESTATÍSTICO DO BRASIL, 1936), em 1936, compreendemos a gravidade dessa realidade, haja vista os altos índices de analfabetismo2. Na década 1920, contrastava no país o seu processo de desenvolvimento de uma economia industrial-urbana, com 23.142.248 de pessoas que não sabiam ler nem escrever, constituindo 75,54 \% de analfabetos, de um total de 30.635.605 pessoas. A erradicação do analfabetismo era primordial para preparar a nação para as novas atividades econômicas. Essa realidade, levava a defesa da expansão da demanda social e de propostas de reforma, somada a preocupação de formação de cidadãos votantes.

A modernização cultural, econômica, industrial e urbana apontava para que democratizasse e uniformizasse o ensino para erradicar o analfabetismo, educar e instruir o povo e prepará-lo para as novas atividades sociais, 180 econômicas e culturais, bem como torná-lo apto a participar da vida política do país. Com a emergência do processo de industrialização no país, verificou-se um crescimento acelerado da demanda social por escola, acompanhado de uma intensa mobilização das elites intelectuais em torno das reformas e da expansão dos sistemas educacionais vigentes constituídos. Era uma resposta aos apelos de uma ideologia importada e faceta de um processo que objetivava se modernizar. Essa nova situação induziu profundas modificações no quadro das aspirações educacionais, no discurso e na ação do próprio Estado (XAVIER, 1990, p. 59).

Tratava-se de um momento em que o país passava por eventos de significativa transformação da sua vida social, política, econômica e cultural. Segundo Nagle (2001), foi um período de convergência da várias formas de pensamento, de correntes de ideias e de atuação de movimentos políticos e sociais em torno da República. Como, por exemplo, o liberalismo³, o coronelismo ${ }^{4}$, o nacionalismo, o modernismo, o tenentismo, as lutas reivindicatórias do operariado, a Semana da Arte Moderna em 1922, as pressões da burguesia pela liberalização econômica e, até mesmo, o entusiasmo pela educação. Essas novas orientações ideológicas demonstravam heterogeneidade 
sociocultural, ora para conservar, ora para reformular a ordem social mais ampla.

Não obstante, havia uma forte preocupação, no que se refere ao voto e à representação, voltada a um ideário liberal composto basicamente pelos elementos: representação e justiça. A plataforma política desse ideário fundamentava-se em um programa de regeneração política, de defesa do voto secreto, de moralização dos costumes políticos e na liberdade individual com medidas de proteção e de regulamentação do trabalho. Esses são sinais de um pensamento liberal que tentava se reformar a partir da base ${ }^{5}$. Nesse processo, a escolarização era considerada fundamental.

Os movimentos preocupados com a constituição do campo educacional como área de política setorial do Estado e a constituição de novos sujeitos políticos nacionais voltados especificamente para o ensino ocuparam um espaço importante na política do país. As transformações nos setores econômicos e políticos fizeram surgir um novo sistema de valores da civilização urbano-industrial, provocando alterações no mercado e nas relações de trabaIho. A modernização cultural, econômica, industrial e urbana apontava para a que democratizasse e uniformizasse o ensino para erradicar o analfabetismo, educar e instruir o povo e prepará-lo para as novas atividades sociais, econômicas e culturais.

Nesse clima de contestações de ideias e de transformações de práticas sociais, econômicas e políticas, a educação passou a ser pensada, analisada e tratada como estratégia de construção nacional e como uma atividade de caráter profissional, exercida por homens públicos e por educadores intelectuais. Sobressaiu a figura do técnico, uma nova categoria profissional, que iria tratar dos assuntos educacionais para enfrentar o grande desafio de eliminar o analfabetismo, formar o povo com um espírito cívico nacional para exercer novas atividades econômicas e modernizar o Estado.

Brasil experimentou a necessidade de uma organização de funcionários especialmente treinados. Era a busca racional, sistemática e especializada de pessoal treinado e especializado para atender tanto as expectativas de um Estado que pretendia se modernizar como as expectativas da vida econômica, uma vez que tais elementos ganharam importância para a ordem social do país (WEBER, 1999). Ou seja, o essencial era transformar os indivíduos em força produtiva, eliminar a falta de instrução e a ignorância 
legado do Manifesto de 32 à educação brasileira: os desafios persistem

popular que dominava o país. Essa situação provocava certa instabilidade na estrutura política, econômica e social do país.

Isso constituiu um fato histórico "[...] em que se forjaram os recursos políticos de modernização do Estado e da sociedade através da constituição do campo educacional como área de política setorial do Estado nacional" (ROCHA, 2004, p. 18). O perfil pretendido exigia novos modelos de relações sociais, econômicas, políticas, culturais e educacionais, dando origem a pensamentos e crenças que se transfiguravam em atuações voltadas para reformar a sociedade, a partir da reforma do homem.

Diante dessa nova compreensão, o problema da insuficiência do atendimento escolar elementar e os altos índices de analfabetismo passaram a ser tratados por educadores de profissão ${ }^{6}$ e por políticos. $\bigcirc$ país poderia se desenvolver e se modernizar pela atividade econômica e pela utilização de aptidões individuais. A educação poderia contribuir e atuar no aperfeiçoamento da sociedade tendo em vista a modernização do Estado, mediante reformas educacionais promovidas pelos educadores brasileiros.

A educação passou a atuar sobre a sociedade com o intuito de transformá-la e de adequá-la a uma modernidade comprometida com os ideais liberais de igualdade, conectada à atividade econômica moderna, segundo os princípios de cooperação e solidariedade. Temos, como exemplo, a reforma mineira de Francisco Campos, no final da década de 1920, quando foi proposta uma concepção de educação transformadora do meio. "A educação está comprometida com a civilização e com o progresso. Ela visa à superação do obscurantismo, da superstição e do servilismo em nome da formação moral, da inteligência e da autonomia dos sujeitos" (ROCHA, 2004, p. 81 ).

Iniciou-se, assim, um processo em prol da escola no qual ela passou a assumir a responsabilidade de atuar sobre a sociedade com o intuito de transformá-la e com base em uma dimensão pedagógica. Esse contexto político ideológico favoreceu a retomada dos ideais liberais do início da República e realçou uma nova orientação pedagógica denominada escolanovismo.

Em defesa da escola foi criada, em 1924, a Associação Brasileira de Educação (ABE), que se constituiu em um espaço propício à divulgação de um novo ideário educacional, organizando a primeira Conferência Nacional de Educação. As reformas educacionais implementadas nas décadas de 1920 e 1930 representaram a materialização das discussões em torno da instrução 
pública, com o objetivo de reformar a educação para remodelar a sociedade, como parte de um plano de racionalização da educação e reeducação da sociedade para modernizar o Estado (ROCHA, 2004).

As principais reformas educacionais foram implementadas nos estados federados por educadores e políticos, tais como Lourenço Filho, Anísio Teixeira, Fernando de Azevedo, Carneiro Leão, Francisco Campo, os quais assumiram uma posição progressista e introduziram, de maneira decisiva e sistemática, ideias inovadoras assentadas nos conhecimentos científicos racionais e técnicos voltados para a racionalização do ensino com vistas a modernizar o Estado (LEMME, 1984; XAVIER, 1990).

A escola ofertada estava aquém da necessidade do país republicano, embora existissem esses esforços em prol da educação. As propostas antecipavam os novos ares explicitados no Manifesto e mantinham relação direta com o novo espírito da República, instaurada a partir de 1930.

\section{As propostas e a estrutura do Manifesto}

Por meio da ABE, foi convocada a IV Conferência Nacional para pressionar o governo a definir e assumir uma política nacional para a educação. Esta se realizou no Rio de Janeiro, em dezembro de 1931, sob o tema "As grandes diretrizes da educação popular". Getúlio Vargas, como chefe do Governo Provisório, abriu o evento e manifestou que estava empenhado na obra de reconstrução do país. Comprometendo-se a acatar as decisões, convocou os educadores para encontrar uma "fórmula feliz" para definir "o sentido pedagógico" da Revolução de 1930 (LEMME, 1984).

Vinte e seis educadores assinaram o Manifesto, e muitos deles se tornaram intelectuais emblemáticos na história da educação brasileira, como Fernando de Azevedo, Lourenço Filho, Paschoal Lemme, Cecília Meireles, Afrânio Peixoto, Sampaio Dória, Nóbrega da Cunha, Anísio Teixeira. Este último, juntamente com Azevedo (1971), divulgou amplamente o ideário escolanovista, tinha como pressuposto que a educação era a base de qualquer sociedade civilizada. Em sua visão, a sociedade estava se transformando devido ao desenvolvimento da ciência e, consequentemente, seriam desencadeadas mudanças na escola, onde as ciências tornar-se-iam conteúdos fundamentais. Ele criticava a escola tradicional, que, devido ao seu caráter 
legado do Manifesto de 32 à educação brasileira: os desafios persistem

autoritário, não preparava o homem para as mudanças: era preciso prepará-lo para refletir sobre seus problemas e buscar soluções.

Anísio Teixeira (2000) considerava que, para se atingir a modernização, seria necessário considerar três diretrizes: a ciência, como já explicitamos, a industrialização, que proporcionava o acúmulo de riquezas e o bem-estar social do homem, e a democratização. Por meio da industrialização, os países considerados desenvolvidos não imporiam barreiras à entrada dos demais países ao mercado, uma vez que ela ampliaria o capital financeiro e o trabalho assalariado na maioria deles. A sociedade burguesa tinha produzido o antagonismo de classe e as opressões de classes, a individualidade exacerbada do trabalho e as insatisfações sociais: "[...] e todos esses problemas são problemas para a educação resolver" (TEIXEIRA, 2000, p. 34). Ele atribuía, assim, grande poder à escola, propondo a reforma de ideias sem questionar a base material sobre a qual a sociedade capitalista repousava.

A democracia, para o autor supracitado, foi considerada como uma das diretrizes que exigia a modernização na educação, já que tomava como princípio a existência de homens livres e iguais, com um governo representativo, eleito por sufrágio universal. Essa forma de governo poderia ajudar 184 o Brasil a resolver seus problemas, porque permitiria "[...] a cada indivíduo um lugar na sociedade, correspondendo às suas capacidades naturais, sem qualquer restrição de ordem social, econômica ou de nascimento" (TEIXEIRA, 2000, p. 34). Ignorava, assim, a luta entre burguesia e operariado.

Para Anísio Teixeira (2000), a escola deveria acompanhar as mudanças da sociedade e preparar o homem para as novas necessidades, conservando a estrutura social existente. Para tanto, a escola prepararia para a vida à medida que os indivíduos assimilassem conteúdos de forma sistematizada com o objetivo de compreenderem as relações políticas, sociais e econômicas postas, visando formar o homem bondoso, gentil e tolerante, de acordo com os princípios liberais. Este homem deveria priorizar riqueza, harmonia e liberdade no ambiente de transformação e progresso iniciado com a industrialização, portanto, o modelo social a ser mantido era o modelo burguês. É evidente que Anísio Teixeira (2000) justificava a necessidade de uma outra escola, a escola que prepararia o cidadão necessário a uma sociedade industrial republicana. Em sua primeira edição, o Manifesto apresentava dez itens que resumiam o programa desse documento. 
Esse programa partia de algumas premissas básicas, como a ideia de formação integral e natural do indivíduo, que era concebido como diferente visto que cada um possuía personalidade única e que deveria ser respeitada, exigindo que a escola não tivesse um único método pedagógico, nem que todos aprendessem da mesma forma. $\bigcirc$ que deveria ser comum era a noção de que todos teriam deveres para com a sociedade, deveriam trabalhar, serem disciplinados, cooperativos e solidários (MANIFESTO..., 1932, p. 43). Mais importante do que o conteúdo a ser veiculado estava uma formação moral do indivíduo, que estimulasse a exacerbação do sentimento altruísta com vistas ao bem comum.

Dada a importância atribuída à educação pública, o Estado, entendido como representante da vontade da maioria e acima dos interesses de classes, era o grande educador, para tanto, no orçamento geral, os fundos destinados ao financiamento desse setor deveriam ser destacados. $\bigcirc$ Manifesto mantinha a descentralização, mas permitia que o Estado assumisse uma ação supletiva nos lugares onde não existissem escolas. Assim, a escola, para assegurar um direito democrático, deveria ser gratuita, obrigatória até os 18 anos e leiga, sem nenhuma interferência ou privilégio de qualquer religião. Sobre a supremacia do Estado, Teixeira (1 999) escreveu:

Obrigatória, gratuita e universal, a educação só poderia ser ministrada pelo Estado. Impossível deixá-la confiada a particulares, pois estes somente poderiam oferecê-la aos que tivessem posses lou a protegidos) e daí operar antes para perpetuar as desigualdades sociais, que para removê-las. A escola pública, comum a todos, não seria, assim, o instrumento de benevolência de uma classe dominante, tomada de generosidade ou de medo, mas um direito do povo, sobretudo das classes trabalhadoras, para que, na ordem capitalista, o trabalho [...] não se conservasse servil, submetido e degradado, mas igual ao capital na consciência de suas reivindicações e dos seus direitos (TEIXEIRA, 1999, p. 83).

Reforçava-se, no documento de 1932, a ideia de educação integral, de coeducação dos sexos e de organização de um sistema nacional, prevendo a criação de creches e jardins de infância para assistência aos educandos na fase pré-escolar. A escola primária deveria desenvolver as aptidões individuais dos alunos, independente de sua classe social, "[... reconhecendo a todo o indivíduo o direito a ser educado até onde permitam as suas aptidões naturais, 
independente de razões de ordem econômica e social" (MANIFESTO..., 1932, p. 42). Os alunos que se destacassem por mérito próprio deveriam ter acesso ao ensino secundário. A educação técnico-profissional atenderia às necessidades da sociedade brasileira e, para tanto, era importante criar universidades no país. Essas deveriam formar os professores que atenderiam aos níveis anteriores de forma a tornarem realidade uma nova proposta educacional.

Para que a mudança na estrutura organizacional da escola fosse completa, era preciso adotar métodos e processos de ensino que obedecessem "[...] às mais modernas conquistas das Ciências Sociais, da Psicologia e das técnicas pedagógicas" (LEMME, 1984, p. 265), organizando-se com planos definidos por intermédio de escalas educacionais e constituindo-se num sistema que proporcionasse a aquisição de conhecimentos científicos pelo método da observação, pesquisa e experiência. Combatia-se, desse modo, a velha estrutura do serviço educacional artificial e verbalista, no qual o aluno seria modelado exteriormente, numa reação contra as tendências passivas e intelectualistas da escola tradicional. Na nova escola, a atividade estava na base de todos os trabalhos, "[...] é a atividade espontânea, alegre e fecunda dirigida à 186 satisfação do próprio indivíduo" (MANIFESTO..., 1932, p. 54).

A nova escola não concebia o aluno como um ser que se pudesse modelar exteriormente, mas como um ser possuidor de funções complexas de ações e reações "[...] em que o espírito cresce de 'dentro para fora' [...] e transfere para a criança e para o respeito de sua personalidade o eixo e o centro de gravidade do problema da educação" (MANIFESTO..., 1932, p. 53). Exigia-se, portanto, a transformação da escola pública em todos os seus graus, a escola primária teria supremacia sobre as demais, porque se tornava elemento fundamental das democracias. Assim, formar-se-iam os novos cidadãos votantes, participantes ativos das decisões sociais por meio do exercício do voto. Nesse contexto, a escolarização primária exerceria função primeira e alcançaria um número maior da população, oferecendo iguais condições para o desenvolvimento individual e a mobilização social em função das aptidões individuais.

Em termos gerais, para se estabelecer um sistema de ensino amplo para o Brasil naquele momento, haveria a necessidade de se criar uma estrutura orgânica de educação adequada às características brasileiras, ou seja, as novas diretrizes educacionais tinham como horizonte as condições econômicas 
e sociais da civilização moderna, que se assentaria nos seguintes princípios propostos pelo Manifesto:

a) a educação é considerada, em todos os seus graus, como uma função social e um serviço essencialmente público que o Estado é chamado a realizar com a cooperação de todas as instituições sociais;

b) cabe aos Estados federados organizar, custear e ministrar o ensino em todos os graus, de acordo com os princípios e as normas gerais estabelecidas na Constituição e em leis ordinárias pela União, a quem é de competência a educação na capital do País, uma ação supletiva onde quer que haja deficiência de meios e ação fiscalizadora, coordenada e estimulada pelo Ministério da Educação;

c) o sistema escolar deve ser estabelecido nas bases de uma educação integral; em comum para os alunos de um e outro sexo e de acordo com as aptidões naturais; única para todos e leiga, sendo a educação primária gratuita e obrigatória; o ensino deve tender gradativamente à obrigatoriedade até 18 anos e à gratuidade em todos os graus.

A organização da escola secundária (de seis anos) orientava-se para o tipo flexível, de nítida finalidade social, como escola para o povo, não proposta a preservar e a transmitir as culturas clássicas, mas destinada, pela sua estrutura democrática, a ser acessível e proporcionar as mesmas oportunidades para todos. Além de se pautar sobre a base de uma cultura geral comum, previa as seções de especialização para as atividades de preferência intelectual (humanidades e ciências), ou de preponderância manual e mecânica (cursos de caráter técnico).

Concernente à educação técnico-profissional, de nível secundário e superior, por ter como base a economia nacional, necessitava de diferentes tipos de escolas: a) de agricultura, de minas e de pesca (extração de matérias-primas); b) industriais e profissionais (elaboradores de matérias-primas); c) de transportes e comércio (distribuição de produtos elaborados); e segundo métodos e diretrizes para formar técnicos e operários capazes em todos os graus de hierarquia industrial.

Quanto à criação de universidades no país, os fundamentos essenciais propostos podem ser sistematizados numa organização que pudesse exercer tríplice função: elaborar e criar ciência e, ao mesmo tempo, transmitila e vulgarizá-la, servindo, portanto: 
a) à pesquisa científica e à cultura livre e desinteressada;

b) à formação do professorado para as escolas primárias, secundárias, profissionais e superiores (unidade na preparação do pessoal do ensino);

c) à formação de profissionais em todas as profissões de base científica;

d) à vulgarização ou popularização científica, literária e artística, por todos os meios de extensão universitária.

As ideias e as diretrizes que se procurava concretizar não surgiram espontaneamente das cabeças dos autores, foram impulsionadas pelas transformações vividas na sociedade e por um conjunto de ideias que propagavam a renovação dos métodos e processos de ensino, inspirado, sobretudo, nas ideias de John Dewey (GALIANI, 2009). Esse novo espírito repercutiu nos debates educacionais e se manifestaram nas defesas em prol da ampliação dos bancos escolares e do acesso dos pobres à educação como meio de contribuir para a formação de um novo cidadão trabalhador que atendesse às necessidades de um Brasil urbano e que caminhava rumo à industrialização.

Como o Brasil acumulou um grande déficit histórico em matéria de educação, essa questão não se resolveu com o advento da República. Saviani 188 (2000) pondera que muitas poderiam ser as hipóteses para esse fato, como a adoção do regime descentralizado, ou pela influência das ideias norte-americanas sobre os republicanos, ou, ainda, pelo peso econômico dos fazendeiros de café que temiam perder o poder exercido localmente. Conclui que, independente das razões, a instrução pública não foi assumida como responsabilidade do governo central. A falta de investimentos financeiros na educação perdurou ao longo do século XX, revelando os contornos irregulares da legislação educacional e dos diversos projetos que dela derivam.

Embora o Manifesto tenha causado grande impacto no período em que foi escrito, não gerou ações concretas, seus princípios pedagógicos não foram absorvidos na organização da escola, nitidamente tradicionalista. Isto fez com que os signatários desse documento, juntando-se a outros, redigissem um segundo Manifesto, menos conhecido, mas não menos importante, o Manifesto dos educadores democratas em defesa do ensino público (1959) - Mais uma vez convocados - Manifesto ao Povo e ao Governo. (MANIFESTO..., 1959; 1961). Nesse momento, acentuou-se o debate entre escola pública versus particular, a propaganda defendia a permanência desta última. Tais documentos cobravam do Estado que ofertasse uma educação nova para todas as classes da sociedade, organizando a escola pública como sistema nacional de 
ensino. No final do século XIX, a escola foi requisitada como aquela capaz de preparar o homem para a cidadania, para ensiná-lo a amar a pátria e o trabalho. Mas não foi tarefa fácil criar essa escola, a política nacional era de descentralização, assim a "educação nacional" ainda seria assunto muito debatido no decorrer do século XX (TEIXEIRA, 1999), culminando com a criação dos sistemas nacionais de ensino apenas em 1961, com a aprovação da Lei de Diretrizes e Bases da Educação Nacional, Lei 4.024/1961, contudo, o ensino não foi democratizado. Saviani (2004) resume as dificuldades desse processo e destaca a criação do Ministério da Educação e Saúde Pública nos anos de 1930. Houve tentativas para reorganizar o ensino, mas não logrou sucesso.

Esse quadro nos permite refletir sobre a situação da educação no século XXI, e os dados apresentados evidenciam a dificuldade de resolução das mazelas educacionais. Esses problemas se manifestam nos baixos salários dos professores, na inadequação da formação dos professores, na falta de infraestrutura das escolas, nos materiais escolares inadequados, no desconhecimento no uso das novas tecnologias, número elevado de alunos por sala, nos índices de evasão e repetência que não diminuem, bem como na baixa qualidade do ensino ofertado. Para discutirmos essa questão, recorremos aos indicadores avaliativos do Instituto Nacional de Estudos e Pesquisas Educacionais Anísio Teixeira (Inep) (BRASIL, 2004). Em termos de construção da escola pública, ainda há muito por fazer.

\section{Considerações finais}

Pelo exposto, concluímos que, o movimento de modernização, posto em marcha nos anos 1930, teve, na educação, um dos principais vetores para a transformação da sociedade brasileira. Mas, por outro lado, a educação foi colocada a serviço dos interesses de uma elite dominante, que precisava de pessoas preparadas e dispostas a trabalhar em prol de sua pátria. Entretanto, as iniciativas de organizar a instrução pública e de melhorar e expandir a educação, seria para minimizar a questão do analfabetismo e formar o cidadão brasileiro.

Contudo, persistiam, ainda, as mesmas dificuldades da Primeira República, quais sejam: sociais, políticas, econômicas e culturais, que 
legado do Manifesto de 32 à educação brasileira: os desafios persistem

repercutiram no processo de organização da instrução pública, porque o embate se deu na escassez de recursos materiais, humanos e financeiros, bem como esbarrou em uma estrutura social excludente, em uma economia dependente de base oligárquica e em valores de uma sociedade agrária, tradicional e conservadora, que se preocupou mais em garantir a supremacia política e econômica do grupo agroexportador e em manter o monopólio do café, conservando um sistema de exclusão, bloqueando a melhoria das condições de vida da população e reproduzindo desigualdades sociais.

Nesse cenário, os renovadores e reformadores assumiram uma posição progressista e introduziram, de maneira decisiva e sistemática, ideias educacionais inovadoras, assentadas nos conhecimentos científicos e técnicos, como estratégia de construção nacional e instrumento de controle social, visando a modernizar o Estado brasileiro.

Dessa forma, a reorganização da instrução pública, apresentada no Manifesto de 1932, era reflexo do intenso/tenso debate em torno do esforço para se traçar as normas que pudessem regular o funcionamento do campo educacional, fossem eles municipais ou estaduais. Com esse horizonte, o documento de 1932 sinalizava para o fortalecimento das funções normalizadas do 190 Estado, ou seja, era necessário o estabelecimento de mecanismos capazes de permitir uma melhor orientação e fiscalização das ações educacionais, bem como qualificar a dimensão administrativa e pedagógica do espaço escolar. Além disso, também era intenção do supracitado documento, aprimorar os instrumentos de inspeção do ensino, com o intuito de submeter os serviços educacionais a uma direção eficaz do ponto de vista burocrático. Uma aspiração de políticos e educadores, no sentido de reorganizar a instrução pública do Brasil, tendo como finalidade a modernização da nação via educação.

Portanto, a (re) leitura do Manifesto traz o necessário questionamento do projeto de modernização do país pela via da educação. Essa possibilidade compunha o ideário nacional de modernização da sociedade, mas tinha algo de utópico, visto que educar o povo continha o profundo significado de fazer a massa aderir - sobretudo pelo voto - ao Governo Vargas recém-implantado que trazia a reboque: industrialização, controle social e democracia, dentre outros pontos. $\bigcirc$ resultado foi a imbricação do discurso educacional com o discurso político, em que a política passaria a traçar então os rumos da educação. Essa articulação pode ser vista tanto como uma tentativa de fazer o país desenvolver com base na educação escolar quanto o desejo de construir 
uma nação democrática e com cidadania pela educação. Mas essa intenção, muitas vezes, esbarrou na vontade política e se mostrou em doses controladas, na medida das necessidades e dos interesses da classe dominante. Assim, o movimento de construção do novo regime político, a partir da Revolução de 1930, foi intrínseco aos movimentos de construção dos projetos de educação proposto pelo Manifesto.

Enfim, num primeiro momento, os princípios apresentados pelo Manifesto revelam a intenção de modernizar a educação, mas, por outro lado, expressa uma ação conservadora de parte dos seus signatários, coerente com a perspectiva transformadora que eles defendiam em relação ao período republicano. Num segundo momento, é possível identificar o projeto político de modernizar o Brasil que assume os ideais liberais: assegurar o exercício livre do voto e lutar em prol das liberdades públicas e contra um estado analfabeto, oligárquico e autoritário. A feição moderna desses ideais não ocultava seus traços do conservadorismo que então marcava a sociedade brasileira: via-se a escola como mecanismo de poder pelo qual seria possível inculcar os princípios liberais nas novas gerações por meio da racionalização escolar para garantir a consolidação e continuidade da ordem social, visto que a educação pública possibilitaria, na perspectiva do Manifesto, a concretização do ideário modernizado para o País. Todavia, os signatários do documento também estavam cientes de que a dimensão educacional é um fenômeno complexo, que não se encerra em proposições legais.

\section{Notas}

1 Por intensificação do debate internacional, a partir de meados do século XIX, difundia-se a ideia da necessidade de se criar escola elementar para o povo, ou melhor, escola primária para todos. As discussões tiveram como resultado o Decreto de Leôncio de Carvalho de 1879 (CALVI, 2003) e o Parecer Projeto de Rui Barbosa de 1882 (MACHADO, 2002), por meio dos quais se pretendia organizar o ensino desde o jardim de infância até o ensino superior.

2 De acordo com os dados do IBGE, em 1890 o número absoluto analfabetos no país chegava próximo a 12. 213. 356, ou seja, 85,21\% da população. Já em 1920 a situação não apresenta melhoria expressiva, pois com o crescimento populacional os valores absolutos saltam para 23. 142.248, o que equivale a 75,54\% (ANUÁRIO ESTATÍSTICO DO BRASIL, 1936).

$3 \bigcirc$ uso desta terminologia exige que o esclarecimento de como ele é tomado nesse artigo, por se tratar de um tema complexo, adotamos o significado atribuído por Dewey (1970, p. 34): "[...] ideais do liberalismo: a concepção do bem comum, como medida política e da organização política, da liberdade como traço mais precioso e o verdadeiro selo da individualidade, do 
direito de cada indivíduo ao completo desenvolvimento de suas capacidades." Este significado foi usado como fundamental para traçar as políticas educacionais com vistas à formação do cidadão republicano que viveria em uma sociedade democrática a ser construída.

4 coronelismo foi um arranjo importante que, entre 1898-1930, dominou a República Velha. Desencadeou-se a partir do federalismo implantado na Constituição de 1891, formou a base de estrutura de poder, fomentou-se pelo desenvolvimento das formações oligárquicas e atingiu o seu grau mais elevado na 'política dos governadores' (NAGLE, 2001, p. 10).

5 Esgotado o liberalismo em sua forma clássica tal como proposto nos séculos XVII e XVIII em defesa da propriedade, igualdade e liberdade, vencida a luta contra os resquícios da sociedade feudal, novos desafios se colocam e novas premissas são necessárias sem alterações na base material e são ressignificados no início do século XX: "Todavia, as ideias de liberdade, de individualidade e de inteligência livre têm valor duradouro, mais necessário hoje do que nunca. A tarefa do liberalismo é a de firmar esses valores, de modo a mostrar sua importância intelectual e prática, em face das atuais forças e necessidades" (DEWEY, 1970, p. 53).

6 Tais como Fernando de Azevedo, Lourenço Filho, Carneiro Leão, Anísio Teixeira, entre outros.

\section{Referências}

\section{AZEVEDO, Fernando. A cultura brasileira. São Paulo: EDUSP, 1971.}

BERMAN, Marshall. Tudo que é sólido desmancha no ar: a aventura da modernidade. São Paulo: Companhia das Letras, 1988.

BRASIL. Anuário Estatístico do Brasil. 1936. Estatísticas do século XX. Rio de Janeiro: IBGE, 1936. (v. 2).

Ministério da Educação. Qualidade da educação: uma nova leitura do desempenho dos estudantes da terceira série do Ensino Médio. Brasília: Ministério da Educação/INEP, 2004.

Congresso Nacional. Lei $\mathbf{n}^{\circ}$ 13.005, de 25 de junho de 2014. Plano Nacional de Educação - PNE e dá outras providências. Plano Nacional de Educação: Legislação Federal. 2014. Brasília, 25 jun. 2014, v. 1, n. 1, Seção 1, p. 1-66.

CALVI, Lourdes Margareth. As transformações sociais e a instrução pública: uma análise dos projetos de reforma educacional e dos relatórios ministeriais de 1868 a 1879 no Brasil. 2003. 160f. Dissertação (Mestrado em Educação) - Programa de Pós-Graduação em Educação, Universidade Estadual de Maringá, Maringá, 2003. 
FARIA FILHO, Luciano Mendes de. Instrução elementar no século XIX. In: LOPES, Eliana Marta Teixeira; FARIA FILHO, Luciano Mendes; VEIGA, Cynthia Greive (Org.). 500 anos de educação no Brasil. Belo Horizonte: Autêntica, 2000.

GALIANI, Claudemir. Educação e democracia em John Dewey. Maringá: EDUEM, 2009.

HABERMAS, Jürgen. O discurso filosófico da modernidade. Tradução Luiz Sergio Repa e Rodnei Nascimento. São Paulo: Martins Fontes, 2000.

LEMME, Paschoal. A escola nova e suas repercussões na realidade educacional brasileira. Revista Brasileira Estudos Pedagógicos, Brasília, v. 65, n. 150, p. 255-272, maio/ago. 1984.

MACHADO, Maria Cristina Gomes. Rui Barbosa - pensamento e ação: uma análise do projeto modernizador para a sociedade brasileira com base na questão educacional. Campinas: Autores Associados; Rio de Janeiro: Fundação Casa de Rui Barbosa, 2002.

MANIFESTO dos pioneiros da educação nova. A reconstrução educacional no Brasil. Ao povo e ao Governo. São Paulo: Companhia Editora Nacional, 1932.

MANIFESTO dos educadores democratas em defesa do ensino público (1959). Mais uma vez convocados. Manifesto ao povo e ao Governo. In: LEMME, Paschoal. Educação democrática e progressista. São Paulo: Editorial Pluma, 1961.

$\mathrm{R} \bigcirc \mathrm{CHA}$, Marlos Bessa Mendes da. Matrizes da modernidade republicana: cultura política e pensamento educacional no Brasil. Campinas: Autores Associados; Brasília: Plano, 2004.

SAVIANI, Dermeval. A ideia de sistema nacional de ensino e as dificuldades para sua realização no Brasil no século XIX. In: CONGRESSO LUSO-BRASILEIRO DE HISTÓRIA DA EDUCAÇÃO. 3; 2000, Coimbra. Anais... Coimbra: Universidade de Coimbra, 2000. 1 CD-ROM.

SAVIANI, Dermeval. O legado educacional do "longo século XX" brasileiro. In: SAVIANI, Dermeval; ALMEIDA, Jane Soares; SOUZA, Rosa Fátima; VALDEMARIN, Vera Teresa (Org.). O legado educacional do século XX. Campinas: Autores Associados, 2004.

TEIXEIRA, Anísio. A educação não é privilégio. Rio de Janeiro: Universidade Federal do Rio de Janeiro, 1999.

TEIXEIRA, Anísio. Pequena Introdução à Filosofia da Educação - a escola progressiva, ou a transformação da escola. Rio de Janeiro: DP\&A, 2000. 
WEBER, Max. A ética protestante e o espírito do capitalismo. 14. ed. Tradução M. Irene de Q. F. Szmrecsányi e Tomás J. M. K. Szmrecsányi. São Paulo: Pioneira, 1999.

XAVIER, Maria Elisabete Sampaio Prado. Capitalismo e escola no Brasil: a constituição do liberalismo em ideologia educacional e as reformas do ensino (1931-1961). Campinas: Papirus, 1990.

Profa. Dra. Maria Cristina Gomes Machado Departamento de Fundamentos da Educação Universidade Estadual de Maringá Pesquisadora Produtividade em Pesquisa do CNPq Grupo de Estudos e Pesquisas em História da Educação, Intelectuais e Instituições Escolares e HISTEDBR | GT Maringá E-mail |mcgmachado@uem.br

Prof. Dr. Carlos Henrique de Carvalho Faculdade de Educação

Universidade Federal de Uberlândia Pesquisador Produtividade em Pesquisa do CNPa Grupo de Pesquisa em História e Historiografia da Educação Brasileira E-mail | carloshcarvalho06@yahoo.com.br

Recebido 18 maio 2014 Aceito 18 nov. 2014 